\title{
Violent behavior of patients living in psychiatric residential facilities: A comparison of male patients with different violence histories
}

\author{
Valentina Candini a ${ }^{\text {, }}$ Chiara Buizza ${ }^{\text {a,f }}$, Clarissa Ferrari ${ }^{\mathrm{a}}$, Maria Elena Boero ${ }^{\mathrm{b}}$, Gian Marco Giobbio ${ }^{\mathrm{c}, \mathrm{d}}$, \\ Nicoletta Goldschmidt ${ }^{\mathrm{d}}$, Stefania Greppo ${ }^{\mathrm{d}}$, Laura Iozzino ${ }^{\mathrm{a}}$, Paolo Maggi ${ }^{\mathrm{c}}$, Anna Melegari ${ }^{\mathrm{b}}$, \\ Patrizio Pasqualetti ${ }^{\text {e }}$, Giuseppe Rossi ${ }^{\text {a }}$, Giovanni de Girolamo ${ }^{\text {a,* }}$, for the PERDOVE group
}

COLLABORATORS: The Perdove Group includes: S. Andreose ${ }^{1}$, P. Basso ${ }^{1}$, R. Beneduce ${ }^{1}$, F. Bongiorno ${ }^{4}$, V. Braida ${ }^{2}$, E. Cortini ${ }^{3}$, J. Dagani ${ }^{1}$, F. De Dominicis ${ }^{2}$, A. Di Giovanni ${ }^{3}$, A. Ghilardi ${ }^{6}$, A. Jaretti Sodano ${ }^{2}$, L. Magni ${ }^{1}$, D. Milazzo ${ }^{5}$, E. Lo Presti ${ }^{4}$, L. Paulon ${ }^{5}$, R. Pioli ${ }^{1}$, C. Ricci ${ }^{4}$, L. Rillosi ${ }^{1}$, G. Savio ${ }^{1}$, L. Scaratti ${ }^{1}$, R. Scioli ${ }^{3}$, L. Veneroni ${ }^{4}$, S. Zamburlini ${ }^{2}$, L. Zorzella ${ }^{1}$

${ }^{1}$ IRCCS St John of God Fatebenefratelli, Brescia, Italy

${ }^{2}$ Rehabilitation hospital Beata Vergine della Consolata, Torino, Italy

${ }^{3}$ Hospital Sacro Cuore di Gesù, Pavia, Italy

${ }^{4}$ Hospital Villa Sant'Ambrogio, Milano, Italy

${ }^{5}$ Medical Statistics E Information Technology, Fatebenefratelli Association for Research, Isola Tiberina, Rome, Italy

${ }^{6}$ Dynamic Clinic Unit, Faculty of Medicine and Surgery, University of Brescia, Italy

a IRCCS St John of God Fatebenefratelli, Brescia, Italy

behabilitation hospital Beata Vergine della Consolata, Torino, Italy

c Hospital Sacro Cuore di Gesù, Pavia, Italy

' Hospital Villa Sant'Ambrogio, Milano, Italy

e Medical Statistics E' Information Technology, Fatebenefratelli Association for Research, Isola Tiberina, Rome, Italy

${ }^{\mathrm{f}}$ Dynamic and Clinic Unit, Faculty of Medicine and Surgery, University of Brescia, Italy

\section{A R T I C L E I N F O}

Available online 11 February 2015

\section{Keywords:}

Violence

Aggressive behavior

Mental illness

Residential facility

Recidivism

Predictors

\begin{abstract}
A B S T R A C T
People with severe mental disorders and a history of violence are often seen as a difficult-to-manage segment of the population. In addition, this group is usually characterized by a high risk of crime recidivism, and poor compliance with community and aftercare programs.

To investigate a sample of male patients living in Residential Facilities (RFs) with a history of violent behavior against people and to compare their characteristics with those of never-violent residents; to analyze the associations between aggressive behaviors in the last two years and a history of previous violence; and, to assess the predictors of aggressive behaviors.

This study is part of a prospective observational cohort study which involved 23 RFs in Northern Italy. A comprehensive set of sociodemographic, clinical, and treatment-related information was gathered, and standardized assessments were administered to each participant. Also a detailed assessment of aggressive behaviors in the past two years was carried out.

The study involved 268 males: 81 violent and 187 never-violent. Compared to never-violent patients, violent patients were younger, with a higher proportion of personality disorders, and have displayed an increased number of aggressive behaviors in the last two years. The presence of a history of violent behavior in the past significantly increases the probability of committing aggressive acts in the future.
\end{abstract}

(C) 2015 Published by Elsevier Ltd.

\footnotetext{
* Corresponding author at: IRCCS St John of God Fatebenefratelli, Via Pilastroni, 4, 25125 Brescia, Italy. Tel.: + 390303501590.

E-mail address: gdegirolamo@fatebenefratelli.it (G. de Girolamo).
}

\section{Introduction}

Since 1980 many studies have attempted to analyze the relationship between severe mental disorders and risk of violence (Nederlof, Muris, \& Hovens, 2013). To date, several variables have been identified that appear to be related to an increased risk of psychiatric patients committing 
violent acts (Fazel \& Seewald, 2012; Witt, van Dom, \& Fazel, 2013). A history of violent behavior, a diagnosis of schizophrenia, especially with an early onset, the severity of psychiatric symptoms (e.g., thought disorder, psychopathy, and suspiciousness), a concomitant use of substances/alcohol and the number of previous psychiatric admissions have been identified as risk factors for the occurrence of aggressive behavior in patients with severe mental disorders (Fazel, Gulati, Linsell, Geddes, \& Grann, 2009; Fazel, Langstrom, Hjern, Grann, \& Lichteinstein, 2009).

In Italy, there have been studies which have focused on patients admitted to acute inpatient facilities (Biancosino et al., 2009; Grassi, Peron, Marangoni, Zanchi, \& Vanni, 2001; Grassi et al., 2001, 2006; Mauri et al., 2011; Raja \& Azzoni, 2005). However, data are very limited on the risk of violent behavior in patients living in Residential Facilities (RFs): the latter have completely replaced Mental Hospitals (MHs) for the long-term care of patients with severe mental disorders. From 2001, a nationwide project (the PROGRES-Acuti) counted more than 17,000 residential beds and most likely, that number has increased (de Girolamo et al., 2007 ) in the last 12 years since that survey. During phase 2 of that study, residential patients previously admitted to Forensic Mental Hospitals (FMHs) $(\mathrm{N}=193)$ were compared with the rest of the patients ( $N=2962$ ) surveyed (Preti et al., 2008). Overall, the symptom profile did not differentiate former judiciary patients from residents who had never been admitted to a FMH. Moreover, the rate of violent behaviors reported during the last year was low and limited to a very small group of former FMH patients.

\subsection{The Italian forensic psychiatric system}

The Italian forensic system is based on six FMHs with a total number of 1421 beds, which is a rate of 100 patients per 4.5 million population according to the January 1st, 1997 census (i.e., 2.2 per 100,000; Fioritti, 2005). All admissions and discharges are determined by judicial authorities, and are mainly based on criminal criteria: inmates treated in FMHs can be discharged when judicial authorities establish that they are not 'socially dangerous' anymore (i.e., further crimes by this person are considered unlikely). The rules for the psychiatric assessment of individuals charged with violent crimes are not stringent, and no explicit guidelines or criteria for rendering a verdict of 'not guilty by reason of insanity' have ever been established. The treatment provided in FMHs is mainly custodial and pharmacological, although some small-scale rehabilitation programs are being implemented. Links with standard mental health services are limited and shared programs are rare. The number of people placed in FMHs has not increased since 1980, when the population numbered 1424 patients. In the following years a gradual decrease occurred, until 1998 when the number of forensic patients in Italy was at its lowest ever (977). Since 1999, the opposite trend has emerged, and in the report of the Parliamentary Committee of 2010, the country's six FMHs were detaining 1421 patients. The scientific literature on forensic psychiatric patients in Italy is limited to very few articles, which mostly concern theoretical issues (Fioritti \& Melega, 2000; Russo, Salomone, \& Della Villa, 2003); a recent review on the history of Italian forensic psychiatry has been published by De Vito (2013). Only two follow-up studies of forensic patients have been conducted to date: a five-year retrospective study examining 96 patients who had been discharged from the Barcellona Pozzo di Gotto FMH. Results showed poor liaison with ordinary mental health services and a $23 \%$ rate of crime recidivism, with serious crimes (homicide/attempted homicide) committed in 7\% of cases (Russo, 1994). A more recent and sophisticated study is the MoDiOPG project, which aimed to assess the clinical and psychopathological characteristics of a representative sample of patients treated in three Italian FMHs, with a three-year follow-up after discharge into the community (Fioritti et al., 2001). Neither of these two projects, however, specifically evaluated forensic patients transferred to RFs.

\subsection{The change in the Italian law}

A recent law has been enacted about the treatment of patients with mental disorders, who have been perpetrators of violent acts (Law 17, February 2012, n. 9).

This Law states that, from 31 March 2013, all patients currently hospitalized in the six Italian FMHs (approximately 1400) will have to be gradually discharged and transferred to non-judicial, psychiatric facilities, to be newly established in each of the 21 Italian Regions. These facilities should organize therapeutic pathways, aimed at the rehabilitation and social reintegration of inmates gradually discharged from FMHs. In order to implement these new facilities, the Italian State has made available 120 million euros for year 2012, and 60 million euros for year 2013. This Law demands new complicated tasks to ordinary Departments of Mental Health (DMHs), currently very poorly equipped to deal with forensic patients and their associated risk of violent behavior, and may have relevant consequences both with regard to the public perception of the mentally ill, and for the potential legal implications that the management of these patients may have for psychiatrists and mental health practitioners.

Moreover, so far neither residency programs for psychiatrists, nor training activities promoted by the DMHs have been set up to adequately train mental health practitioners in this field, making them able to learn specific skills necessary for an appropriate management of perpetrators of violent acts.

This will apply to all psychiatric patients who may commit any act of violence in the future as well. It is therefore likely that most of these patients will be referred or treated in RFs, since they generally require long-term care and often lack any social support. The complex management of aggressive and/or violent patients requires integrated, multiprofessional and specialized treatment. In addition, the law imposes new and complex duties to the ordinary Departments of Mental Health $(\mathrm{DMH})$ which will be responsible for their care. It is therefore necessary to better study the aggressive and violent behaviors and the risk of violence among patients living in RFs, in order to identify the most appropriate strategies for prevention and treatment of potentially violent patients (Hodgins, 2001).

The present study is part of a prospective observational cohort study involving St John of God Order's 23 medium-long term RFs in Northern Italy (de Girolamo et al., 2014) aimed at describing the sociodemographic, clinical, and treatment-related characteristics of RF patients during an index period, and to identify discharge-associated predictors and characteristics at 1-year follow-up.

\subsection{Aims of the study}

Aims of the present study are: (Biancosino et al., 2009) to investigate the sociodemographic, clinical, and treatment-related characteristics of a sample of male patients living in RFs with a history of violent behavior against people (so called 'violent patients'); (Bjørkly \& Waage, 2005) to compare the characteristics of violent patients with never-violent residents; (Cohen \& Eastman, 1997) to analyse the associations between aggressive behavior (e.g., verbal, physical and sexual) displayed in two years of observation by the two groups (violent vs neverviolent); and (de Girolamo et al., 2007) to assess the predictors of aggressive and/or violent behavior.

\section{Material and methods}

\subsection{Patient recruitment and assessment}

All male patients residing in the St John of God Order's 23 mediumlong term RFs in September 2010, with a primary psychiatric diagnosis and age younger than 65 years, were recruited. Exclusion criteria were age 65 years or older, and a primary diagnosis of organic mental disorder (i.e. dementia or mental retardation). The study was approved by 
the relevant Ethics Committee, and all participants provided written informed consent prior to evaluation.

A set of standardised instruments, included in a 'Patient Schedule', was administered; all research assistants underwent a centralised instrument administration and rating training.

The standardized instruments were the Brief Psychiatric Rating Scale (BPRS) (Ventura, Green, Shaner, \& Liberman, 1993), the Health of Nation Outcome Scale (HoNOS) (Wing, Beevor, \& Curtis, 1998), and the Personal and Social Performance (PSP) scale, a modified version of the DSM-IV Social and Occupational Functioning Assessment Scale (SOFAS) (Morosini, Magliano, Brambilla, Ugolini, \& Pioli, 2000). The Specific Levels of Functioning (SLOF), recently considered the 'gold standard' in this field (Harvey et al., 2011), was also administered to assess psychosocial functioning and disability.

Cognitive functioning was evaluated with the Repeatable Battery for the Assessment of Neuropsychological Status (RBANS) (Gold, Queern, Iannone, \& Buchanan, 1999).

\subsection{The violent group}

We selected all male patients for whom the treating clinicians reported at least one positive answer to one or more of the following conditions: (i) patients admitted at least once in their lifetime to a JMH for violent acts against people; (ii) patients arrested at least once in their lifetime for violent acts against people; (iii) patients with a documented life history of violent acts against people (including sexual violence). Hence, the 'violent' group consists of patients who have already acted violently against people at least one (before entering the study), while the 'never-violent' group only includes patients who have never committed physical violence against people in the past.

\subsection{Assessment of aggressive behaviors}

For each patient the treating clinicians reported the frequency of aggressive behavior registered during the year before the baseline assessment and during the 1-year follow-up. Aggressive behavior assessed was: shouting, threatening, pushing others, slapping, punching, inappropriate sexual behavior, sexual harassment, and using weapons. These behaviors were grouped into the following three categories: verbal, physical and sexual aggressive behaviors.

\subsection{Statistical analysis}

All analyses were performed with SPSS 21.0. The Chi-square test for categorical variables (or the Fisher exact test, when needed) was used to compare the baseline sociodemographic, clinical and treatmentrelated characteristics of the two groups ('violent' and never-violent patients). The t-tests (or Mann-Whitney U tests when normality assumption was violated) were used for quantitative variables. A series of binary logistic regression models were performed (through the backward stepwise selection method) to evaluate the behavioral and functional predictors of three types of aggressive behavior: verbal, physical and sexual.

Statistical significance was set for all cases at $p<0.05$.

\section{Results}

\subsection{Facility characteristics and restrictiveness}

A total of 23 RFs participated in the study. Most RFs were independent buildings located in suburban areas, with a mean number of 17.5 residents per facility (range 5-29). The RF sample included a total of 22 clinicians, and $80 \%$ had 24 -hour staff rotation.

Standardised assessment instruments were used routinely in most facilities (75\%). Various types of rehabilitative activities were available: social skills training in $80 \%$ of facilities, individual and group psychoeducation in 65\%, job training in 65\%, and expressive/manual activities in all RFs.

All RFs had restrictive rules concerning patients' daily life and behaviour: in $65 \%$ of RFs the staff managed the daily entry and exit for patients and visitors. In $85 \%$ of RFs, residents were allowed to go out autonomously; in $40 \%$ patients allowed to exit had to specify their destination.

In $40 \%$ of RFs all patients were allowed to manage their own money, while in $55 \%$ of RFs this happened only for selected patients. Patients in $40 \%$ of the RFs had fixed bedtimes, generally consisting in the light-off of the bed rooms, and also involved the closure of entrance doors; in 50\% of RFs patients were allowed to refuse their participation in planned activity, while in $40 \%$ they were allowed to do so only occasionally.

All these RFs did not have a structured organization for the specific management of potentially violent patients, including patients with a history of violence, eventually discharged from FMHs.

\subsection{Sample's characteristics}

A total of 268 male patients met the study entry criteria and were assessed at baseline: 81 were violent patients and 187 never violent ones. Table 1 shows the differences between the two groups with regard to their main sociodemographic and clinical characteristics; missing data were few and never exceeded $8 \%$.

The mean age of violent patients was 46.5 years $(S D=9.5$; median 47 ), compared to 47.7 ( $S D=10.2$; median 49 ) of never-violent patients. In terms of age distribution, the violent group was younger than the never-violent. The majority of patients had a schizophrenia spectrum diagnosis, but violent patients were more likely to have a personality disorder, compared to never-violent patients.

The mean RF stay duration was 3.1 years $(S D=3.5$; median 1.9$)$ in the violent group, and 4.0 years ( $\mathrm{SD}=6.5$; median 2.1 ) in the neverviolent patients. Conversely, the mean illness duration was 21.6 years $(\mathrm{SD}=11.1$; median 22$)$ in the violent group, and 22.1 years $(\mathrm{SD}=$ 12.0; median 20) in the never-violent group; these differences were not statistically significant.

Regarding the ability to cooperate in the previous year, 47 (58\%) patients of the violent group were actively cooperative with the treatment, compared to 104 (55.9\%) of the never-violent group.

\subsection{Standardized assessment scores}

At entry, the mean total score of BPRS and HONOS was similar in both groups. Looking at single items of the BPRS, there were statistically significant differences between the two groups in hostility, grandiosity, suspiciousness, motor slowing, and conceptual disorganization. Violent patients had a PSP higher score than never-violent patients, indicating a better functioning.

With regard to the SLOF, there were statistically significant differences between both groups in two areas: 'activities' and 'work skills'. Even in this case, violent patients exhibited a higher score, indicating a better psychosocial functioning.

Lastly, the mean total RBANS score (neuropsychological status) was similar in the two groups, indicating the presence of a mild cognitive impairment for both groups. (See Table 2.)

\subsection{Aggressive behaviors in the observation period}

Table 3 shows the difference in the occurrence of aggressive behavior during the observation period (two years) between violent patients and never-violent patients. There were significant differences between both groups in the occurrence of aggressive behavior: aggressive behavior observed among violent patients was significantly more common than among never-violent patients for all categories of aggressive behavior assessed including verbal, physical and sexual behaviors. 
Table 1

Characteristics of violent and never violent patients. (The numbers in bold show the different values of test of significance.)

\begin{tabular}{|c|c|c|c|c|c|}
\hline & & Violent patients $\mathrm{N}=81 \mathrm{~N}(\%)$ & Never violent patients $\mathrm{N}=187 \mathrm{~N}(\%)$ & $\chi^{2}$ Test & $p$ value \\
\hline \multirow[t]{2}{*}{ Age } & $18-45$ & 37 (45.7) 44 & $72(38.5) 115$ & 1.206 & NS \\
\hline & $46-64$ & (54.3) & (61.5) & & \\
\hline Marital status & Currently married or cohabiting Alone & 9 (11.1) $72(88.9)$ & $11(5.9) 176(94.1)$ & 2.238 & NS \\
\hline \multirow[t]{2}{*}{ Education } & Low level & $64(79.0) 17$ & $157(84.0) 30$ & .956 & NS \\
\hline & Medium-High level & $(21.0)$ & $(16.0)$ & & \\
\hline \multirow[t]{2}{*}{ Occupation } & Employment & $6(7.4)$ & $9(4.8)$ & .720 & NS \\
\hline & Unemployed & $75(92.6)$ & $178(95.2)$ & & \\
\hline \multirow[t]{2}{*}{ Primary diagnosis } & Schizophrenic disorders & $55(70.5)$ & $127(83.0)$ & & \\
\hline & Personality disorder & $23(29.5)$ & $26(17.0)$ & 4.825 & .028 \\
\hline \multirow{3}{*}{ Lifetime compulsory admissions } & None & $18(22.5)$ & $105(57.1)$ & 26.797 & $<.001$ \\
\hline & $1-3$ & $40(50)$ & $50(27.2)$ & & \\
\hline & $\geq 4$ & $22(27.5)$ & $29(15.8)$ & & \\
\hline \multirow{2}{*}{$\begin{array}{l}\text { History of deliberate } \\
\text { Self-harm and suicide attempts }\end{array}$} & Yes & $38(46.9)$ & $72(38.5)$ & 1.652 & NS \\
\hline & No & $43(53.1)$ & $115(61.5)$ & & \\
\hline \multirow[t]{2}{*}{ Social support } & Available & $29(35.8)$ & $62(33.5)$ & .131 & NS \\
\hline & Absent & $52(64.2)$ & $123(66.5)$ & & \\
\hline \multirow[t]{2}{*}{ Predicted discharge after 12 months } & In the same RF or in another RF & $60(74.1)$ & $161(87.0)$ & 6.725 & .010 \\
\hline & At home & $21(25.9)$ & $24(13)$ & & \\
\hline
\end{tabular}

\subsection{Predictors of aggressive behavior}

Table 4 shows the results of the logistic regression models. The assignment to the group of violent patients is itself a predictor of aggressive behaviors in the two years of observation: patients who belong to the violent group (i.e. who had a history of violence against people in the past) were more likely to commit verbal ( $\mathrm{OR}=2.4,95 \% \mathrm{CI}$ : $1.3-4.2$ ), physical ( $\mathrm{OR}=2.3,95 \% \mathrm{CI}: 1.3-4.3$ ) and sexual aggression ( $\mathrm{OR}=6.3,95 \% \mathrm{CI}: 2.3-17.1)$ than the never-violent patients. With regard to sexual aggression, the results of the logistic regression should be considered with caution, due to the very low number of those events in the sample.

The second logistic regression assessed the likelihood of the escalation from verbal to physical aggression, and from physical to sexual aggression in the violent group. Data indicated that being in the violent group increased the probability of escalation in both cases.

Finally three logistic regression analyses were performed with verbal, physical, and sexual aggression (assessed with yes/no) as dependent variables, and all BPRS items as independent variables. Several BPRS items show a predictive value about the likelihood of committing different types of violent acts. In the first model, higher scores on items covering

Table 2

Statistically significant differences in scorings of rating scales between violent and never violent patients. (The numbers in bold show the different values of test of significance.)

$\begin{array}{lccrl} & \begin{array}{l}\text { Violent } \\ \text { patients } \\ (\mathrm{N}=81)\end{array} & \begin{array}{l}\text { Never violent } \\ \text { patients } \\ \text { mean }(\mathrm{ND})\end{array} & \begin{array}{l}\text { Test } \\ \text { mean }(\mathrm{SD})\end{array} & p \text { value } \\ & 59.7(18.9) & 59.6(17.2) & .315 & \mathrm{NS}^{\#} \\ & 1.5(0.7) & 1.6(0.9) & -.818 & \mathrm{NS}^{\#} \\ \text { BPRS } & 2.8(1.8) & 2.4(1.5) & 1.970 & \mathbf{. 0 5 0}^{\#} \\ \text { Suicidality } & 2.5(2.0) & 1.9(1.5) & 2.018 & \mathbf{. 0 4 6}^{\#} \\ \text { Hostility } & 3.6(1.9) & 2.9(1.7) & 2.896 & \mathbf{. 0 4 0}^{\#} \\ \text { Grandiosity } & 2.5(1.8) & 3.0(1.9) & -2.080 & \mathbf{. 0 3 9}^{\#} \\ \text { Suspiciousness } & 1.6(1.0) & 1.9(1.3) & -2.385 & \mathbf{. 0 1 8}^{\#} \\ \text { Conceptual disorganization } & 19.5(8.0) & 20.0(8.1) & -.446 & \mathrm{NS}^{*} \\ \text { Motor slowing } & 44.2(15.9) & 37.9(13.8) & 3.253 & \mathbf{. 0 0 1}^{*} \\ \text { HONOS } & & & & \\ \text { PSP } & 3.4(0.9) & 3.2(0.9) & 1.775 & \mathrm{NS}^{*} \\ \text { SLOF } & 4.3(0.7) & 4.5(0.5) & 1.680 & \text { NS }^{*} \\ \text { Interpersonal } & 3.7(1.2) & 3.4(1.2) & 1.992 & \mathbf{. 0 4 7}^{*} \\ \text { Acceptable behavior Community } & 3.1(1.3) & 2.6(1.1) & 2.744 & \mathbf{. 0 0 7}^{*} \\ \text { Activities } & 71.9(12.6) & 69.9(11.1) & 1.110 & \text { NS }^{*} \\ \text { Work skills } & & & & \\ \text { RBANS } & & \end{array}$

\footnotetext{
* Parametric t-test.

\# Non-parametric Mann-Whitney U test.
}

hostility and grandiosity increase the likelihood of committing verbal aggression, while motor slowing and somatic concern decrease it.

The second model shows that higher scores on items covering hostility, disorientation and tension increase the probability of committing physical aggression; on the contrary, self-neglect is associated to a lower probability.

Lastly, higher scores on items related to motor hyperactivity and suspiciousness increase the likelihood of committing sexual aggression, while un-cooperativeness decreases it.

\section{Discussion}

\subsection{Patients' profile}

People with severe mental disorders and a history of violent offences are usually seen as a difficult-to-manage population. They are characterized by a high risk of crime recidivism, poor compliance with community and aftercare programs, and homelessness (Dolan \& Doyle, 2000; Jamieson \& Taylor, 2002; Teplin, 1990).

In our study we analyzed a variety of risk factors associated with violence; these factors are generally divided in two categories: the first category is represented by 'Static Risk Factors', historical factors which do not frequently fluctuate and include characteristics such as young age, marital status, a previous history of violence, and psychiatric diagnosis. The second consists of 'Dynamic Risk Factors', more likely to change and fluctuate over relatively short periods of time, such as treatment compliance/non-compliance, psychiatric symptoms, suicidal thoughts, and community support. We assessed their specific role in the occurrence of new violent behavior, and here we will discuss the main findings.

Table 3

Occurrence of aggressive behavior during the two years of observation in the two groups.

\begin{tabular}{|c|c|c|c|c|}
\hline & $\begin{array}{l}\text { Violent patients } \\
(\mathrm{N}=81) \mathrm{N}(\%)\end{array}$ & $\begin{array}{l}\text { Never violent patients } \\
(\mathrm{N}=187) \mathrm{N}(\%)\end{array}$ & $\chi^{2}$ test & $p$ value \\
\hline \multicolumn{5}{|c|}{ Verbal aggression } \\
\hline Yes & $32(40)$ & $41(21.9)$ & 9.21 & .002 \\
\hline No & $48(60)$ & $146(78.1)$ & & \\
\hline \multicolumn{5}{|c|}{ Physical aggression } \\
\hline Yes & $24(30)$ & $29(15.5)$ & 7.39 & .007 \\
\hline No & $56(70)$ & $158(84.5)$ & & \\
\hline \multicolumn{5}{|c|}{ Sexual violence } \\
\hline Yes & $14(17.3)$ & $6(3.2)$ & 16.21 & .000 \\
\hline No & $67(82.7)$ & $181(96.8)$ & & \\
\hline
\end{tabular}


Table 4

Logistic regression models for aggressive behaviours.

\begin{tabular}{llrl}
\hline & & OR & 95\% CI \\
\hline A) Models & & & \\
Dependent variables & Independent variables & & \\
A1) Verbal aggression (yes vs no) & Violents (yes vs no) & 2.4 & $1.3-4.2$ \\
A2) Physical aggression (yes vs no) & Violents (yes vs no) & 2.3 & $1.2-4.3$ \\
A3) Sexual aggression (yes vs no) & Violents (yes vs no) & 6.3 & $2.3-17.1$ \\
& & & \\
B) Models (escalation toward more & dangerous aggressions) & & \\
Dependent variables & Independent variables & 16.0 & $8.1-34.5$ \\
B1) Physical aggression (yes vs no) & Verbal aggression (yes vs no) & 16.9 \\
B2) Sexual aggression (yes vs no) & Physical aggression (yes vs no) & 2.9 & $1.2-7.7$ \\
& & & \\
C) Models & & & \\
Dependent variables & BPRS independent variables & \\
C1) Verbal aggression (yes vs no) & Motor slowing & 0.7 & $0.5-1.0$ \\
& Hostility & 2.3 & $1.8-3.1$ \\
& Somatic concern & 0.7 & $0.6-0.9$ \\
& & & \\
C2) Physical aggression (yes vs no) & Hostility & 1.5 & $1.2-1.8$ \\
& Self-neglect & 0.7 & $0.6-0.9$ \\
& Disorientation & 1.4 & $1.1-1.7$ \\
& Tension & 1.2 & $1.0-1.5$ \\
& & & \\
C3) Sexual aggression (yes vs no) & Motor hyperactivity & 1.7 & $1.2-2.3$ \\
& Suspiciousness & 1.3 & $1.0-1.7$ \\
& Un-cooperativeness & 0.7 & $0.5-1.0$
\end{tabular}

\footnotetext{
* Only significant independent variables are reported. OR: Odds ratios, 95\% CI: 95\%
} confidence interval.

In our study, patients with a history of violence against people were younger, and had a higher prevalence of personality disorders. These data confirm what is already noted in literature, which demonstrates that younger patients have a greater chance of being admitted for violent behavior (Walker \& Caplan, 1993). Other studies, on the contrary, did not reveal significant differences with regard to patients' age (Miller, Zadolinnyj, \& Hafner, 1993). Indeed, violent patients had more compulsory/mandatory admissions in their lifetime.

With most assessment instruments, violent patients were rated as similar to never-violent patients and the symptom profile was comparable in both groups. However, the violent group showed higher BPRS scores in specific areas, which usually define the clinical and psychopathological characteristics of people who act violently (i.e. hostility, grandiosity, suspiciousness, conceptual disorganization, and motor slowing).

Finally, in our study, violent patients had a better psychosocial functioning. In an Italian study comparing severe judicial patients to age, sex and diagnosis-matched outpatients (the MoDiOPG study), judicial patients displayed a mild profile of social, occupational, and physical disability; when compared with community controls, violent inmates more frequently had less severe social disabilities (Fioritti et al., 2001, 2006). An explanation of these results might be that patients who were violent were admitted to RFs because of their violence, whereas nonviolent patients were referred because of their low functioning and poor ability to care for themselves. Moreover, patients with a lower psychosocial functioning and a reduced social activity have less chance, patterns, and ability to plan, organize and commit violent acts. Finally, we did not collect information regarding the neurocognitive profiles of these patients; since this dimension is relevant to define their psychopathological features, these variables could play an important role in explaining predictive and risk factors for violence acted by patients with severe mental disorders.

\subsection{Aggressive behaviors and predictors of violence}

In our study, the occurrence of aggressive behavior (e.g., verbal, physical and sexual aggressive behaviors) by violent patients during the two years of observation was significantly higher than that among the never-violent patients. Even the results of the logistic regression show that committing violent acts in the past increases the likelihood of committing new violent acts in the future. Past violent behavior is a predictor of aggressive behavior (e.g., verbal, physical and sexual) in the future.

Moreover, violent patients even had a higher propensity for selfharm than never-violent residents, although this difference was not statistically significantly. This data might confirm the statistically higher risk of death by suicide among violent detained subjects both in Italy as elsewhere (Preti \& Cascio, 2006).

In terms of clinical implications, interventions aimed at reducing hostility and grandiosity might be associated to a lower risk of verbal aggression; similarly, the reduction of tension, hostility and disorientation may decrease the likelihood of committing physical aggression. Thus, controlling and treating these important psychopathological dimensions may be helpful in the prevention of violent acts.

These observations should also be taken into account in the training of staff managing those patients, and these clinical aspects should be carefully evaluated in planning both pharmacological and behavioral treatments.

\subsection{Planning new services for violent patients}

In recognition of the risk of recidivism by people who have already committed violent acts (Lund, Hofvander, Forsman, Anckarsäter, \& Nilsson, 2013), it is important to increase all the efforts to provide adequate services within the correctional settings as well as support for viable community treatment alternatives. This is particularly urgent in Italy, where the recent legislation calls for a significant change in the care of psychiatric patients who act violently. Since FMHs will have to be shut down and replaced by community facilities (yet to be designed), it is imperative to better study the problem of violence associated to severe mental disorders and to design effective treatment strategies. Indeed living in the community, for the great majority of offenders with serious mental disorders, depends on the availability of appropriately supportive and structured living arrangements (Cohen \& Eastman, 1997; Lamb, Weinberger, \& Gross, 1999). When patients are not suitable to live with their own family or are unable to live independently (as it is often the case), the availability of RFs can become a critical factor in the provision of support and clinical supervision, and in preventing recidivism in this population.

To date very little is known about if, and how, RFs can meet the everyday needs of patients with a history of violent behavior. As stressed by many authors, more investigations aimed at evaluating risk of reoffending in this group of patients are needed (Bjørkly \& Waage, 2005; Heilbrun et al., 2011; Hodgins \& Müller-Isberner, 2004; Holliday, Heilbrun, \& Fretz, 2012). Our study, conducted in the specific setting of RFs, is a contribution into that direction.

\subsection{Limitations}

The present study presents some limitations. First, patients were not assessed with structured diagnostic interview, and therefore, diagnostic reliability might be limited. The risk of drawing inferences on misdiagnosed participants, however, can be considered relatively low, given that broad diagnostic categories were used and that diagnoses were made by treating clinicians after a long period of close inpatient observation. Furthermore, direct interviews with patients were not conducted-a procedure that may have resulted in a few inaccuracies. Most of the questions, however, were easily answered by the facility managers and staffs based on detailed medical records, while behaviors during the 1-year follow-up were carefully recorded by treating staffs, and this has greatly mitigated the risk of miscollection.

Secondly, since this study was not specifically designed to evaluate violent patients, the clinical assessment did not include more sophisticated instruments investigating neuropsychological and neurochemical correlates, as well as social cognition. In the current literature, in fact, 
these dimensions are relevant to define the psychopathological profiles of these patients (Fabian, 2010; Solomon, Aladeokin, \& Eduviere, 2013).

\section{Conclusions}

Our data show that the relationship between severe mental disorders and violent behavior is still a controversial topic. However, more and more studies show that both static and dynamic factors are associated with a higher risk of violence, but their specific role and relevance can depend on a variety of situational and individual factors. So far most investigations have been aimed at examining violent patients' adjustment after their release from RFs to the community and at evaluating their risk of reoffending. While these studies are important, it is equally relevant to study whether, and how, RFs meet the everyday needs of patients with a history of antisocial behavior, in order to organize these facilities as effectively and safely as possible and make possible the dismantling of backward custodial institutions.

\section{Acknowledgements}

The study was supported by a grant from the Associazione Fatebenefratelli for Research (AFAR). We thank Fra Marco Fabello for his valuable support in conducting this study. The authors have no conflict of interest regarding this paper.

\section{References}

Biancosino, B., Delmonte, S., Grassi, L., Santone, G., Preti, A., Miglio, R., et al. (2009). Patterns of care in patients discharged from acute psychiatric inpatient facilities: A national survey in Italy. The Journal of Nervous and Mental Disease, 197(10), 772-782.

Bjørkly, S., \& Waage, L. (2005). Killing Again: A Review of Research on Recidivistic SingleVictim Homicide. International Journal of Forensic Mental Health, 4, 1.

Cohen, A., \& Eastman, N. (1997). Needs assessment for mentally disordered offenders and others requiring similar services. Theoretical issues and methodological framework The British Journal of Psychiatry, 171, 412-416.

de Girolamo, G., Barbato, A., Bracco, R., Gaddini, A., Miglio, R., Morosini, P., et al. (2007). Characteristics and activities of acute psychiatric in-patient facilities: National survey in Italy. The British Journal of Psychiatry, 191, 170-177.

de Girolamo, G., Candini, V., Buizza, C., Ferrari, C., Boero, M. E., Giobbio, G. M., et al. (2014). Is psychiatric residential facility discharge possible and predictable? A multivariate analytical approach applied to a prospective study in Italy. Social Psychiatry and Psychiatric Epidemiology, 49(1), 157-167.

De Vito, C. G. (2013). Forensic psychiatric units in Italy from the 1960s to the present. International Journal of Law and Psychiatry, 37(1), 127-134.

Dolan, M., \& Doyle, M. (2000). Violence risk prediction. Clinical and actuarial measures and the role of the Psychopathy Checklist. The British Journal of Psychiatry, 177 303-311.

Fabian, J. M. (2010). Neuropsychological and neurological correlates in violent and homicidal offenders: A legal and neuroscience perspective. Aggression and Violent Behavior 15(3), 209-223.

Fazel, S., Gulati, G., Linsell, L., Geddes, J. R., \& Grann, M. (2009). Schizophrenia and violence: Systematic review and meta-analysis. PLoS Medicine, 6, 1-15.

Fazel, S., Langstrom, N., Hjern, A., Grann, M., \& Lichteinstein, P. (2009). Schizophrenia substance abuse, and violent crime. JAMA, 301, 2016-2023.

Fazel, S., \& Seewald, K. (2012). Severe mental illness in 33,588 prisoners worldwide: Systematic review and meta-regression analysis. The British Journal of Psychiatry, 200(5), 364-373.

Fioritti, A. (2005). Italy. In H. J. Salize, \& H. Dressing (Eds.), Placement and treatment of mentally ill offenders: Legislation and practice in the European Union (pp. 260-271). Lengerich, Germany: Pabst.

Fioritti, A., Ferriani, E., Rucci, P., \& Melega, V. (2006). Characteristics of homicide perpetrators among Italian forensic hospital inmates. International Journal of Law and Psychiatry, 29, 212-219.

Fioritti, A., \& Melega, V. (2000). Psichiatria Forense in Italia: una storia ancora da scrivere. Epidemiologia e Psichiatria Sociale, 9, 219-226.

Fioritti, A., Melega, V., Ferriani, E., Rucci, P., Scaramelli, A. R., Venco, C., et al. (2001). Crime and mental illness: An investigation of three Italian forensic hospitals. The Journal of Forensic Psychiatry \& Psychology, 12, 36-51.

Gold, J. M., Queern, C., Iannone, V. N., \& Buchanan, R. W. (1999). Repeatable battery for the assessment of neuropsychological status as a screening test in schizophrenia, I:
Sensitivity, reliability, and validity. The American Journal of Psychiatry, 156(12), 1944-1950.

Grassi, L., Biancosino, B., Marmai, L., Kotrotsiou, V., Zanchi, P., Peron, L., et al. (2006). Violence in psychiatric units: A 7-year Italian study of persistently assaultive patients. Social Psychiatry and Psychiatric Epidemiology, 41(9), 698-703.

Grassi, L., Peron, L., Marangoni, C., Zanchi, P., \& Vanni, A. (2001). Characteristics of violent behavior in acute psychiatric in-patients: A 5-year Italian study. Acta Psychiatrica Scandinavica, 104(4), 273-279.

Harvey, P., Raykov, T., Twamley, E., Vella, L., Heaton, R., \& Patterson, T. (2011). Validating the measurement of real-world functional outcomes: Phase I results of the VALERO study. The American Journal of Psychiatry, 168(11), 120-1195.

Heilbrun, K., Dematteo, D., Brooks, S., Yasuhara, K., Shah, S., Anumba, N., et al. (2011). Risk-need assessment: Bridging disciplinary and regional boundaries. Criminal Behavior and Mental Health, 21(1), 1-7.

Hodgins, S. (2001). The major mental disorders and crime: Stop debating and start treating and preventing. International Journal of Law and Psychiatry, 24, 427-446.

Hodgins, S., \& Müller-Isberner, R. (2004). Preventing crime by people with schizophrenic disorders: The role of psychiatric services. The British Journal of Psychiatry, 185, 245-250.

Holliday, B., Heilbrun, K., \& Fretz, R. (2012). Examining improvements in criminogenic needs: The risk reduction potential of a structured re-entry program. Behavioral Sciences \& the Law, 30(4), 431-447.

Jamieson, E., \& Taylor, P. J. (2002). Follow-up of serious offender patients in the community: Multiple methods of tracing. International Journal of Methods in Psychiatric Research, 11(3), 112-124.

Lamb, H. R., Weinberger, L. E., \& Gross, B. H. (1999). Community treatment of severely mentally ill offenders under the jurisdiction of the criminal justice system: A review. Psychiatric Services, 50(7), 907-913.

Lund, C. Hofvander, B., Forsman, A. Anckarsäter, H. \& Nilsson, T. (2013). Violent criminal recidivism in mentally disordered offenders: A follow-up study of 13-20 years through different sanctions. International Journal of Law and Psychiatry, 36, 250-257.

Mauri, M. C., Rovera, C., Paletta, S., De Gaspari, I. F., Maffini, M., \& Altamura, A. C. (2011). Aggression and psychopharmacological treatments in major psychosis and personality disorders during hospitalisation. Progress in Neuro-Psychopharmacology \& Biological Psychiatry, 15,35(7), 1631-1635.

Miller, R. J., Zadolinnyj, K., \& Hafner, R. J. (1993). Profiles and predictors of assaultiveness for different psychiatric ward populations. The American Journal of Psychiatry, 150(9), $1368-1373$

Morosini, P. L., Magliano, L., Brambilla, L., Ugolini, S., \& Pioli, R. (2000). Development, reliability and acceptability of a new version of the DSM-IV social and occupational functioning assessment scale (SOFAS) to assess routine social functioning. Acta Psychiatrica Scandinavica, 101(4), 323-329.

Nederlof, A. F., Muris, P., \& Hovens, J. E. (2013). The epidemiology of violent behavior in patients with psychotic disorder: A systematic review of studies since 1980. Aggression and Violent Behavior, 18, 183-189.

Preti, A., \& Cascio, M. T. (2006). Prison suicides and self-harming behaviors in Italy, 19902002. Medicine, Science and the Law, 46(2), 127-134.

Preti, A., Picardi, A., Fioritti, A., Cappiello, V., Santone, G., de Girolamo, G., et al. (2008). A comparison between former forensic and non-forensic patients living in psychiatric residential facilities: A national survey in Italy. The Journal of Forensic Psychiatry E' Psychology, 19(1), 108-126.

Raja, M., \& Azzoni, A. (2005). Hostility and violence of acute psychiatric inpatients. Clinical Practice and Epidemiology in Mental Health, 1,11.

Russo, G. (1994). Follow-up of 91 mentally ill criminals discharged from the maximum security hospital in Barcelona P.G. International Journal of Law and Psychiatry, 17, 279-301.

Russo, G., Salomone, L., \& Della Villa, L. (2003). The characteristics of criminal and noncriminal mentally disordered patients. International Journal of Law and Psychiatry, 26, 417-435.

Solomon, U., Aladeokin, A. C., \& Eduviere, A. T. (2013). Aggressive behavior: A comprehensive review of its neurochemical mechanisms and management. Aggression and Violent Behavior, 18(2), 195-203.

Teplin, L. A. (1990). The prevalence of severe mental disorder among male urban jail detainees: Comparison with the Epidemiologic Catchment Area Program. American Journal of Public Health, 80(6), 663-669.

Ventura, J., Green, M. F., Shaner, A., \& Liberman, R. P. (1993). Training and quality assurance with the Brief Psychiatric Rating Scale: The drift busters. International Journal of Methods in Psychiatric Research, 3(4), 221-244.

Walker, W. D., \& Caplan, R. P. (1993). Assault behavior in acute psychiatric wards and its relationship to violence in the community: A comparison of two health districts. Medicine, Science and the Law, 33(4), 300-304.

Wing, J. K., Beevor, A. S., \& Curtis, R. H. (1998). Health of the Nation Outcome Scale (HoNOS). Research and development. The British Journal of Psychiatry, 174, 432-434.

Witt, K., van Dom, R., \& Fazel, S. (2013). Risk factors for violence in psychosis: Systematic review and meta-regression analysis of 110 studies. PLOS ONE, 8(2), e55942. 